AperTO - Archivio Istituzionale Open Access dell'Università di Torino

\title{
Endocrine Autoimmunity in Down's Syndrome
}

\section{This is the author's manuscript}

Original Citation:

\section{Availability:}

This version is available http://hdl.handle.net/2318/1634312

since 2019-04-25T23:16:04Z

Publisher:

Karger

Published version:

DOI:10.1159/000452912

Terms of use:

Open Access

Anyone can freely access the full text of works made available as "Open Access". Works made available under a Creative Commons license can be used according to the terms and conditions of said license. Use of all other works requires consent of the right holder (author or publisher) if not exempted from copyright protection by the applicable law. 


\section{Endocrine Autoimmunity in Down's Syndrome}

Federica Guaraldi ${ }^{1}$, Roberta Giordano ${ }^{1,2}$, Ruth Rossetto Giaccherino ${ }^{1}$, Fabio Lanfranco ${ }^{1}$, Giovanna Motta ${ }^{1}$, Davide Gori ${ }^{3}$, Emanuela Arvat ${ }^{4}$, Ezio Ghigo ${ }^{1}$

${ }^{1}$ Division of Endocrinology, Diabetes and Metabolism, Department of Medical Sciences, University of Turin, Turin, Italy

${ }^{2}$ Department of Clinical and Biological Science, University of Turin, Turin, Italy

${ }^{3}$ School of Hygiene and Preventive Medicine, Department of Biomedical and Neuromotor Sciences (DIBINEM), Alma Mater Studiorum University of Bologna

${ }^{4}$ Division of Oncological Endocrinology, Department of Medical Sciences, University of Turin, Turin, Italy

\section{Correspondence to:}

Federica Guaraldi, M.D., Ph.D.

Division of Endocrinology, Diabetes and Metabolism

Department of Medical Sciences

University of Turin

I-10126, Turin, Italy

Telephone: +390116334316

Fax: +390116334769

E-mail: federica.guaraldi@unito.it 


\begin{abstract}
Since the mid 1900s, a significant increase of infectious, hematological and autoimmune diseases has been reported in patients with Down's syndrome (DS), independently from sex, age, family history and exposure to other risk factors, suggesting an intrinsic alterations of the immune system. Several in vitro and in vivo studies have demonstrated alterations of both cellular and humoral immunological response mainly, although not exclusively, secondary to alterations of the expression of AIRE (autoimmune regulator) gene (located on chromosome 21), leading to thymic structural and functional impairment. Autoimmune thyroid disorders (i.e. Hashimoto's thyroiditis and Graves' disease) and type 1 diabetes mellitus are the most common autoimmune endocrine disorders associated with DS, and present with some peculiar features. The underlying etiopathogenic mechanisms and clinical significance of some mild laboratory alterations are still poorly understood. For these aspects, together with the associated multiple comorbidities and intellectual impairment that make DS patients dependent on care givers -, and the absence of definite guidelines, disease management is very challenging and should be patient-tailored.
\end{abstract}




\section{Introduction}

Down's Syndrome (DS), firstly described by J. L. Down in 1866, is the commonest chromosomal aneuploidy in live newborns and the main cause of genetic intellectual disability in Western countries [1-3]. Estimated incidence varies from 1/700 to 1/1,500 live births, depending on prenatal diagnostic procedures, age at conception - as the risk increases with maternal age for the higher frequency of maternal chromosome 21 non-disjunction -, gestational timing of diagnosis, and case loss due to abortion. DS is caused by chromosome 21 trisomy (non-disjunction) in $95 \%$ of the cases, while the remaining ones are due to parental or de novo translocations or mosaicism [1-3].

DS presents with pathognomonic physical characteristics, muscle hypotonia, mental retardation, accelerated and atypical ageing, and is variably associated with cardiovascular, digestive, immunological and thyroid disorders, increased risk of hematologic malignancies and early-onset Alzheimer's disease, overall strongly impacting on life quality and expectancy [2-4].

This chapter presents the hypothetical etiopathogenic mechanisms underlying immune dysregulations in DS, describes the main features of DS-associated autoimmune endocrine diseases, and discusses unsolved issues related to their diagnostic and therapeutic management, from neonatal age to adulthood.

\section{Mechanisms underlying immune alterations and predisposition to autoimmune diseases in patients with Down's syndrome}

Since the 1970s, various studies have been performed to identify immunological alterations responsible for the increased incidence of infections, autoimmune diseases and hematological malignancies observed in patients with DS [5-7]. Thymic atrophy and reduction in leucocytes and lymphocytes count have been repeatedly reported in these patients since the neonatal age [7], together with an inadequate expansion of B and $\mathrm{T}$ lymphocytes in response to the huge exposure to environmental antigens in the first years of life, irrespective of the frequency of infections or development of autoimmunity $[5 ; 6 ; 8 ; 9]$. T lymphocytes gradually reach normal levels over the time, while B lymphocytopenia persists. Moreover, after the age of 5 years, DS subjects present with excessive IgA and IgG - with high levels of IgG1 and IgG3 and low levels of IgG2 and IgG4 - but reduced IgM, overall responsible for an exaggerated response to food antigens and auto-antigens, but a poor 
production of natural antibodies, that worsens from childhood to adult age [7]. Moreover, a marked reduction of circulating CD4+, paralleled by an increase of CD8+ lymphocytes, has ben reported, related, at least in part, to the increase of natural killer (NK) cells expressing CD8 antigen. Finally, the percentage of CD3+ and CD5+ cells, capable of non-MHC restricted cytotoxicity, is significantly increased. These alterations could be related to both intrinsic B-cells defects and deficient T-cells help, secondary due to thymic dysfunction [5; 7] as pathognomonic histological thymic alterations, responsible for altered T-cells production and maturation, and interactions between B and T cells have been described in DS [5-7; 9].

AIRE (autoimmune regulator) gene located in the $21 \mathrm{q} 22.3$ region and selectively expressed in thymic medullary epithelial cells, modulates the transcription of some genes encoding for peripheral tissue-restricted antigens (TRAs), crucial for the negative selection of developing thymocytes, control of antigen presentation, chemokines' production and maturation $[6 ; 10]$. Inactivating AIRE mutations lead to autoimmune polyendocrine syndrome type I (APS1), an autosomal recessive disease that shares specific autoantibodies with DS but different disease patterns. Hypoparathyroidism and Addison's disease, hallmarks of APS1, are extremely rare in DS patients, while Hashimoto's thyroiditis, Graves' disease (GD) and type 1 diabetes mellitus are the most typical DS-associated endocrine autoimmune diseases [10]. Contrasting data regarding thymic expression of AIRE in DS have been reported. Gimenez-Barcons et al. observed a significant reduction of its expression despite the presence of three copies of the gene, suggesting overcompensation of the excess of gene dosage by post-transcriptional regulation [6]. On the contrary, Skogberg et al. reported increased AIRE levels: given the complexity of AIRE effects on thymic function, it is not surprising that AIRE overexpression could be associated with impaired thymic function and structure [10].

Because an adequate thymic expression of self-antigens is crucial for central tolerance, even a modest reduction may importantly contribute to the predisposition to autoimmunity, as demonstrated in patients with type 1 diabetes, myasthenia gravis and GD in which genetic polymorphisms result in reduced thymic expression of the target auto-antigens (insulin, a-chain of the acetylcholine receptor, and TSH receptor, respectively) [6;10].

Finally, alterations in the extracellular adenine nucleotides and nucleosides (i.e. ATP and adenosine) involved in the regulation of inflammation through the stimulation of pro- and anti-inflammatory cytokines -, and in the enzymes that control the extracellular levels of these molecules have been recently recognized as factors contributing to immune dysregulation in DS [11]. 


\section{Thyroid disorders in Down's syndrome: main features and therapeutic implications from neonatal to}

adult age

Thyroid disorders are the most common endocrinopathy in DS, with a prevalence ranging from 7 to $66 \%$, depending on variations in study sample size and age (the risk significantly increase with age [12]), laboratory assays, diagnostic criteria and study design $[1 ; 3 ; 13]$.

Several in vitro and in vivo studies have demonstrated an increased oxidative stress in DS, that may be responsible for accelerated aging and immunological disturbances, and appears to be caused by an excessive enzymatic activity of superoxide dismutase 1 (SOD1) and other alterations in genes involved in mithocondrial function and metabolism of reactive oxygen species (ROS), coded on the extra copy of chromosome 21 [3; 14].

Thyroid hormones are major modulators of cell metabolism and oxidative stress, as they stimulate both catabolic and anabolic reactions, and regulate the synthesis and degradation of proteins, vitamins and antioxidant enzymes, and the mitochondrial respiratory rate [3; 15]. Data on oxidative stress associated with thyroid dysfunction are scarce and controversial. An increased oxidative stress has been reported as in both hypo- and hyperthyroidism, even in subclinical forms, despite their opposed effects on metabolism, in patients with and without DS [3]. Some alterations in the mechanisms regulating oxidative stress that may contribute to thyroid dysfunction in DS include: low levels of selenium, required for the synthesis and metabolism of thyroid hormones and functioning of selenium-dependent antioxidant enzymes, that protect the thyrocytes against peroxides; impairment of phenylalanine hydroxylase activity, converting phenylalanine in tyrosine; and DYRK1A kinase overexpression, that reduces tyrosine availability [3].

The spectrum of thyroid disorders reported in DS include congenital hypothyroidism (1-3.6\%), isolated hyperthyrotropinemia or subclinical hypothyroidism (12.5-32.9\%), primary hypothyroidism (0.3-3.2\%), autoimmune thyroiditis (0.3-1.4\%) and hyperthyroidism (0-2\%) [16]. Epidemiological, clinical and management features typical of each condition are discussed in the following paragraphs.

\section{Hypothyroidism}

Hypothyroidism is the most common thyroid alteration in DS. It can be congenital (incidence 1/141 live DS births vs. 1/2,500-5,000 in newborns without DS) or acquired [17-21].

In the first years of life, hypothyroidism distribution is balanced between sexes, in contrast with the 
typical association with female gender observed in non DS people. Most of the patients present with subclinical hypothyroidism $(\mathrm{SH})$ or hyperthyrotropinemia, defined as mildly elevated thyroid-stimulating hormone (TSH < $10 \mathrm{mUI} / \mathrm{l}$ ) in the presence of normal levels of free thyroxine (fT4) and triiodiothyronine (fT3), with no clinical symptoms or laboratory/ecographic signs of thyroid autoimmunity [22]. Thus, diagnosis is essentially made by routine biochemical screening [17-21; 23-25].

In the majority of the cases, the underlying cause remains undetermined [17-21;23-25]. According to a study by Luton et al. performed in 13 fetuses between 23 and 33 weeks of gestation, thyroid morphology and localization is normal, while immunohistochemistry demonstrated abnormally small and heterogeneous follicles, with delayed maturation, particularly regarding the expression of TTF1 (thyroid transcription factor 1), encoded by $N k x 2.1$ gene, a follicular cell marker during early development and a transcription factor involved in thyroid function later on, suggesting a primary defect in thyroid development as the basis of TSH elevation. TSH levels were $>80^{\text {th }}$ percentile, and, in the great majority of the cases, fT4 levels were $<50^{\text {th }}$ percentile [26]. In DS fetuses and newborns, thyroid hypoplasia is rather frequent, while thyroid agenesis, ectopy or goiter are extremely rare; anti-thyroid antibodies are detected only in a minority of patients and TSH levels are not apparently related to thyroid volume $[17 ; 19 ; 23 ; 24]$.

Several hypothetical pathogenic mechanisms have been postulated, including:

I. exaggerated response to thyroid-releasing hormone (TRH) stimulation. A study by Sharav et al. [27] demonstrated higher mean TSH levels in basal conditions and after TRH-stimulation test, but normal fT4 and fT3 and negative anti-thyroid antibodies in DS children aged 1 month -7 years old, as compared to healthy agematched subjects. TRH test performed in the follow-up in 14 DS patients demonstrated an exaggerated response up to the third year of life, then declining to normal levels, suggesting a delayed maturation of the hypothalamic-pituitary-thyroid axis;

II. inappropriate TSH secretion secondary to peripheral resistance to thyroid hormones: in DS cell membranes have abnormal biochemical, physiological and receptor functions, potentially affecting thyroid hormone receptor function [27];

III. a central disorder causing inappropriate TSH release, or an inadequate dopaminergic TSH-regulation. As dopamine inhibits TSH secretion acting both on the hypothalamus and pituitary receptors, an altered dopaminergic control could be responsible for thyroid dysfunction. Some studies have described atrophy and reduction in the number of dopamine-producing cells in the substantia nigra at the base of the brain, ventral 
tegmental area and in the hypothalamic arcuate nuclei - the latter inhibiting TSH secretion - in DS patients aged over 40 years old $[17 ; 24 ; 27 ; 28]$;

IV. hyper-responsiveness to interferon (IFN) due to over-expression of the genes coding for IFN-receptor 1 and 2 , located on chromosome 21 . This theory is based on the observation that IFN $\alpha$ can precipitate thyroiditis by immune modulatory mechanisms and have direct thyroid toxic effects in vivo, while it down regulates gene expression of the proteins involved in T4 synthesis and secretion in vitro [17; 24];

V. self-limiting asymptomatic autoimmune process. A variable prevalence (7.5 - 39\%) of ab-TPO is reported in DS subjects, mainly depending on the age of the investigated subjects, as anti-thyroid antibodies usually appear in late childhood and their incidence increase with age, but independently from gender $[12 ; 16 ; 17 ; 24 ; 29]$;

VI. imbalance of dosage-sensitive genes interfering with T4 production. This hypothesis is suggested by the normal mean thyroglobulin concentration and plasma TSH bioactivity, together with the higher dose of 1thyroxine required to normalize plasma thyrotrophin (T4) levels, and the presence of anti-peroxidase antibodies (ab-TPO) only in a minority of patients [30].

Hypothyroidism may also be caused by Hashimoto's thyroiditis (HT), that represents the most common endocrine autoimmune disorder associated with DS, typically presenting in late childhood - early adulthood. Main features differentiating HT in DS subject from the general population and deserving clinical attention are: 1) the more severe biochemical picture, despite the significantly lower levels of anti-thyroid antibodies; 2) the increased risk of SH, probably because of coexisting congenital alteration in the regulation of thyroid function; 3) the younger age at presentation, possibly related also to the major pediatricians awareness on the risk of thyroid alterations in DS, leading to early investigation in suspicious cases; 4) the absence of female predominance, 5) the very low frequency of HT family history and 6) the frequent association with other autoimmune disorders, mainly celiac disease, type 1 diabetes and alopecia, all supporting the hypothesis of DS as a risk factor for autoimmune disorders per se; and7) the mild or absent manifestations in most of the cases $[25 ; 31 ; 32]$.

In patients with DS and autoimmune thyroiditis, a peculiar association was found with the MHC class II DQA 0301 allele, expressed on chromosome 6, whose activity may be up-regulated by immune regulatory genes located on chromosome 21, thus favoring autoimmunity. At the same time, no correlations between HLA genotype and thyroid dysfunction or presence of antithyroid antibodies have been clearly demonstrated [25; 33]. 


\section{Management of hypothyroidism in Down's Syndrome subjects}

The most appropriate management of SH remains largely debated in DS because of the very frequent presence of thyroid alterations of unknown clinical significance in this population and the dubious beneficial effects associated with treatment $[21 ; 24 ; 34]$.

A recent observational study performed in 428 DS patients and 1,166 age- and sex-matched healthy subjects aged 6 months - 64 years, demonstrated a wider distribution of TSH values in DS group with a tendency towards higher values, especially in subjects aged $>15$ years, with no associated symptoms, and the presence of antibodies only in a minority of patients [22]. Myrelid et al. [18] demonstrated that the presence of SH detected by neonatal screening is not associated with an increased risk of hypothyroidism in childhood, nor impaired development. A very low annual incidence of new cases of hypothyroidism has been reported in adult DS subjects euthyroid or with SH at baseline followed for 10 to 15 years [35; 36]. Numerous other studies showed that hypothyroidism is often transient with spontaneous resolution and no significant differences in growth and development between DS children with SH and euthyroidism $[3 ; 12 ; 13 ; 16 ; 21 ; 23 ; 25 ; 29]$. Based on these data, a "wait and see" policy is recommended in DS subjects with SH, reserving treatment to overt hypothyroidism or TSH $>10 \mu \mathrm{U} / \mathrm{ml}$ associated with goiter and/or ab-TPO, because of the increased risk of progression towards to overt HT in these cases [32]. Treatment can be also considered in SH in absence of other risk factors, but requires an off-treatment re-evaluation as the picture can resolve $[3 ; 21 ; 34-36]$.

On the contrary, according to other authors, thyroid function screening in DS is justified because the natural history of thyroid disease is well established, the risk of silent hypothyroidism is significant, the problem is easily detectable, has a latent phase, and the treatment is easy and cheap [37]. In recent times, capillary blood sampling from a finger prick test has been proposed a less invasive, more tolerated and more practical alternative to venipuncture for thyroid screening, although it is limited to the determination of TSH, and is poorly sensitive for mildly increased TSH values $(<10 \mathrm{mUI} / \mathrm{l})$, thus requiring venipuncture in borderline cases. Mc Gowan et al. suggest annual capillary sample in children over 5 years old as it can detect elevations of TSH levels for which therapy is necessary, being the risk of decompensated hypothyroidism in patients with mildly elevated TSH very low. Venipuncture should be probably preferred as screening approach in children before 5 years of age as they are more vulnerable and even a mild thyroid insufficiency could lead to severe consequences on brain maturation [37]. 
Some authors have demonstrated that mild hypothyroidism could persist or progress toward an overt form - especially in presence of anti-thyroid antibodies and/or goiter -, that could be missed as symptoms (i.e. fatigue, dry skin, impaired memory and speech and weight gain) are unspecific and can be present in DS patients without hypothyroidism $[12 ; 17 ; 23-25 ; 28 ; 29 ; 34]$. Moreover, hypothyroidism, even subclinical forms, may have detrimental effects on muscle tone, anemia [38], cardiac function (pericardial effusion may be the first sign of hypothyroidism [3]), intellectual development and statural growth [30;34;39]. Indeed, hypothyroidism may contribute, in association with other factors, to reduce peripheral tissue sensitivity to growth hormone $(\mathrm{GH})$, as somatotroph axis function is normal, and L-thyroxine treatment can improve growth [38], especially when diagnosis and treatment are prompt [30].These data justify thyroid screening and therapy in SH in DS newborns $[30 ; 34 ; 38 ; 39]$.

In summary, periodical screening of thyroid function, together with auxological and clinical evaluation in DS children, aimed at early identifying and treating those progressing to overt hypothyroidism or becoming symptomatic is advised, although optimal screening frequency and target populations (universal newborn screening vs. symptomatic subjects) is still discussed [24; 32]. Regarding 1-thyroxine replacement therapy in children with SH, arguments in favor of treatment include the lack of adverse side effects associated with 1thyroxine replacement, the potential beneficial treatment effects on growth and intellectual development, otherwise retarded in patients with TSH elevation [39] and the prevention of disease progression towards severe hypothyroidism associated with physical and intellectual detrimental effects. On the other side, the uncertain clinical relevance of minor TSH and T4 abnormalities, the fact that TSH increase is typically mild and transient or self-limiting, and that the real benefits associated with 1-thyroxine are not clearly established, do not strongly justify a life-long treatment $[12 ; 25 ; 35 ; 36]$.

Various countries have compiled guidelines for the management of thyroid function in DS subjects, specifically addressing issues related to screening indications, timing and methods, as well as indications for replacement therapy. Because most of the subjects with thyroid dysfunction present with no or few unspecific manifestations, all guidelines agree about the need for screening since birth aimed at early detecting thyroid alterations, thus avoiding associated physical and intellectual impairment. On the other hand, indications on timing (table 3) and methods to monitor thyroid function during follow-up are divergent [40-44].

Regarding treatment, according to the UK and Irish DSMIG guidelines [40], isolated mild elevation (TSH between upper normal level and $10 \mathrm{mUL} / \mathrm{ml}$ ) or the presence of anti-thyroid antibodies in the absence of 
clinical symptoms does not warrant treatment, but should be monitored clinically and biochemically more frequently, for the increased risk of uncompensated hypothyroidism as transient changes in thyroid function may occur. No indications are provided regarding management of SH in either American or Australian guidelines [41; 42].

No economic analysis on the value of annual testing for thyroid function in subjects with DS has been performed, except for a rapid cost evaluation by the National Primary Care Research and Development Centre and University of York Health Economics Consortium in 2009 [45]. The analysis was based on available literature data on the prevalence and incidence of hypothyroidism and hyperthyroidism in DS subjects, and hypothesizing detrimental effects associated with missed diagnosis of these conditions, and the intention to treat with medical therapy (1-thyroxine for hypothyroidism and carbimazole for hyperthyroidism) all identified cases, independently from symptoms. According to study results, annual testing for thyroid function is suggested in DS as it appears relatively inexpensive and can lead to some modest improvements in patient quality of life through earlier intervention; moreover, additional costs associated with patient management (therapy and follow-up testing) is relatively modest. Main limitations of this analysis are the assumption of $100 \%$ of test accuracy - thus not considering potential false positive or negative results leading to unnecessary or delayed treatment, respectively -, and the adoption of a simple decision analytic model which assumes that inputs remain constant over time.

\section{Hyperthyroidism}

Hyperthyroidism, although much less common than hypothyroidism, is significantly more represented in DS than in the general population (estimated prevalence 0.66-3\%). It is mainly caused by Graves' disease (GD), and typically occurs between late childhood and early adulthood [24; 46; 47].

The diagnosis is typically based on the clinical picture and not on regular screening [47]. GD in DS differs from the general population for 1) younger age at diagnosis; 2) the absence of female predominance and 3) the frequent association with other autoimmune disorders, suggesting an underlying genetic predisposition for autoimmune disorders, irrespective of other concomitant risk factors, as observed in HT [46; 47]; 4) the higher tendency to progress from HT to GD, independently from previous 1-thyroxine treatment, thyroid function, iodine levels or autoimmunity at baseline [31; 48]; and 5) short duration of clinical remission under carbimazole treatment [46]. Biochemical and clinical presentation does not substantially differ between DS and 
non-DS patients, except for a possible lower prevalence of ophthalmopathy, although not confirmed by all studies [46].

Treatment is definitely necessary for overt thyrotoxicosis, while it is still debated in subclinical disease, especially in children where the condition may be transient. Intercurrent infections may decompensate hyperthyroidism into thyroid storm, requiring prompt treatment. The best therapeutic approach remains debated and the choice among medical, surgical and radioiodine treatment depends on the clinical picture but also on the expected compliance of the patient and his caregivers. Medical treatment requires regular drug assumption, typically for long periods of time and relapse can occur [13; 47]; moreover, some studies have demonstrated a lower efficacy of medical treatment in DS than in general population [46; 47]. On the other side, radioiodine is a definite treatment in the great majority of the cases, although the risk of secondary hypothyroidism; thus, the need of a life-long replacement therapy is high [13]. Surgery should be reserved for those with serious side effects from thyrostatic drugs or requiring rapid resolution of thyrotoxicosis, as craniofacial abnormalities and short neck could make anesthesia difficult in DS patients [24].

\section{Type 1 diabetes mellitus}

Compared to the general population, patients with DS present a significantly higher risk to develop type 1 diabetes (DM1), being DS the most common genetic syndrome associated with DM [49]. A nationwide population-based study performed in Denmark on children born from 1981 to 2001 demonstrated a 4.2-fold increase in prevalence of DS in DM1 than in general population (0.38\% vs. $0.09 \%)$, corresponding to a prevalence also more than 4 -fold higher (0.7 vs. $0.17 \%)$ [50]. Previous studies reported even higher prevalence, but were biased for the study group selection and diagnostic method [50-52]. Median age of DM1 onset also appears anticipated in DS. One study performed in the 1960s showed a peak of onset at 8 years of age in DS, compared to 14 years in children without DS [53]. In another study, 22\% of DS patients developed DM1 before 2 years of age, compared with only $7 \%$ of children from the general population [54]. A more recent study including 159 DS children diagnosed with DM1 demonstrated a biphasic distribution, with one peak of incidence occurring before the age of 2 years, and a second peak in the early adolescence. Moreover, DM1 in DS is often associated with other autoimmune disorders, mainly autoimmune hypothyroidism and celiac disease [49-52; 55]. 
A very high frequency of anti-glutamic acid decarboxylase antibodies (GADA) has been reported in DS subjects developing DM1. Moreover, DS diabetic patients, independently from age at onset, present with DR4-DQ8/ DR3-DQ2 HLA class II genotype, which is the HLA genotype most strongly associated with DM1also in the general population, suggesting a common ethiopathogenesis. These features are similar between DS and non-DS subjects developing DM1, indicating that DM1 has the same HLA associations in DS and in the general population $[51 ; 52 ; 55]$.

Despite the established association between DM and DS, international guidelines for the management of subjects with DS do not provide specific indications for the optimal age and methods for screening, frequency and method for follow-up in GADA-positive patients considered at higher risk to develop DM1, nor diabetes treatment (i.e. insulin types and daily frequency of administration).

Compared to non-DS diabetic patients, DS diabetic patients tend to be treated with simpler insulin regimens - to improve the patient's and care giver's therapeutic compliance - [49; 52], and have a better control of glycemic and blood pressure levels, possibly related to a simpler lifestyle and acceptance of routine [52; 56]. Consequently, diabetic complications (i.e. retinopathy and nephropathy) are significantly less frequent [56].

\section{Final remarks and conclusions}

Autoimmune disorders are significantly more common in Down's syndrome than in the general population, independently from age, sex and family history, suggesting chromosome 21 trisomy to be a risk factor per se for immune dysregulation. Autoimmune thyroiditis and type 1 diabetes mellitus are the most typical endocrine autoimmune disorders associated with DS, and often present together and in association with celiac disease. In vivo and in vitro studies have identified alterations in both B- and T-cell compartments associated with chromosome 21 trisomy, secondary to thymic dysfunction associated with impaired AIRE gene's expression. At the same, the exact etiopathogenic mechanisms underlying the predisposition of DS subjects to develop autoimmune diseases, as well as the clinical significance of mild biochemical thyroid alterations in the absence of antibodies and clinical manifestations, remain to be defined. Because the frequency of thyroid disorders and diabetes is very high and often misdiagnosed (as manifestations are unspecific and often masked by mental retardation), regular life-long screening of thyroid function and glycemic controls is strongly suggested. No general agreement exists about the optimal timing for screening, follow-up controls or 
for starting treatment in asymptomatic patients with mild hormonal alterations, thus management is mainly based on physician's experience and has to be individualized and tailored both on the patient's and care giver's need. Multicenter, randomized, long-term studies are strongly advised to better define the still unsolved issues and improve management of DS patients. 


\section{Legend to tables}

Table 1: Main characteristics of prospective studies investigating thyroid function in patients with Down's Syndrome

Table 2: Prevalence of thyroid dysfunctions (hyperthyrotropinemia or subclinical hypothyroidism, hypothyroidism and hyperthyroidism) in patients with Down's Syndrome reported by cross-sectional studies

Table 3: Recommendations for the screening and follow-up of thyroid function in patients with Down's syndrome 


\section{References}

1. Real de Asua D, Quero M, Moldenhauer F, Suarez C: Clinical profile and main comorbidities of Spanish adults with Down syndrome. Eur J Intern Med2015;26:385-391.

2. Weijerman ME, de Winter JP: Clinical practice. The care of children with Down syndrome. Eur J Pediatr 2010; 169:1445-1452.

3. Campos C, Casado Á: Oxidative stress, thyroid dysfunction \&amp; Down syndrome.Indian J Med Res $2015 ; 142: 113-119$.

4. Zigman WB: Atypical aging in Down syndrome. Dev Disabil Res Rev 2013; 18:51-67.

5. de Hingh YC, van der Vossen PW, Gemen EF, Mulder AB, Hop WC, Brus F, de Vries E: Intrinsic abnormalities of lymphocyte counts in children with down syndrome. J Pediatr 2005;147:744-747.

6. Giménez-Barcons M, Casteràs A, Armengol Mdel P, Porta E, Correa PA, Marín A, Pujol-Borrell R, Colobran R: Autoimmune predisposition in Down syndrome may result from a partial central tolerance failure due to insufficient intrathymic expression of AIRE and peripheral antigens. J Immunol 2014; 193:3872-3879.

7. Nespoli L, Burgio GR, Ugazio AG, Maccario R: Immunological features of Down's syndrome: a review. J Intellect Disabil Res 1993; 37:543-551.

8. Pellegrini FP, Marinoni M, Frangione V, Tedeschi A, Gandini V, Ciglia F, Mortara L, Accolla RS, Nespoli L: Down syndrome, autoimmunity and T regulatory cells. Clin Exp Immunol 2012; 169:238-243.

9. Verstegen RH, Driessen GJ, Bartol SJ, van Noesel CJ, Boon L, van der Burg M, van Dongen JJ, de Vries E, van Zelm MC:Defective B-cell memory in patients with Down syndrome. J Allergy Clin Immunol 2014; 134:1346-1353.

10. Skogberg G, Lundberg V, Lindgren S, Gudmundsdottir J, Sandström K, Kämpe O, Annerén G, Gustafsson J, Sunnegårdh J, van der Post S, Telemo E, Berglund M, Ekwall O: Altered expression of autoimmune regulator in infant down syndrome thymus, a possible contributor to an autoimmune phenotype. J Immunol 2014;193:2187-2195.

11. Rodrigues R, Debom G, Soares F, Machado C, Pureza J, Peres W, de Lima Garcias G, Duarte MF, Schetinger MR, Stefanello F, Braganhol E, Spanevello R: Alterations of ectonucleotidases and acetylcholinesterase activities in lymphocytes of Down syndrome subjects: relation with inflammatory parameters. Clin Chim Acta 2014;433:105-110. 
12. Gibson PA, Newton RW, Selby K, Price DA, Leyland K, Addison GM: Longitudinal study of thyroid function in Down's syndrome in the first two decades. Arch Dis Child 2005; 90:574-578.

13. Ali FE, al-Busairi WA, al-Mulla FA: Treatment of hyperthyroidism in Down syndrome: case report and review of the literature. Res Dev Disabil 1999; 20:297-303.

14. Pagano G, Talamanca AA, Castello G, Cordero MD, d'Ischia M, Gadaleta MN, Pallardò FV, Petrovic S, Tiano L, Zatterale A: Oxidative stress and mithocondrial dysfunction across broad-related pathologies: toward mithocondria-targeted clinical strategies. Oxid Med Cell Longev 2014;2014:541230.

15. Villanueva I, Alva-Sanchez C, Pacheco-Rosado J: The role of thyroid hormones as inductors of oxidative stress and neurodegeneration. Oxid Med Cell Longev 2013;2013:218145.

16. Iughetti L, Predieri B, Bruzzi P, Predieri F, Vellani G, Madeo SF, Garavelli L, Biagioni O, Bedogni G, Bozzola M:Ten-year longitudinal study of thyroid function in children with Down's syndrome.Horm Res Paediatr 2014; 82:113-121.

17. Cebeci AN, Güven A, Yıldız M: Profile of hypothyroidism in Down's syndrome. J Clin Res Pediatr Endocrinol 2013; 5:116-120.

18. Myrelid A, Jonsson B, Guthenberg C, von Döbeln U, Annerén G, Gustafsson J: Increased neonatal thyrotropin in Down syndrome.Acta Paediatr 2009; 98:1010-1013.

19. Purdy IB, Singh N, Brown WL, Vangala S, Devaskar UP: Revisiting early hypothyroidism screening in infants with Down syndrome. J Perinatol 2014; 34:936-940.

20. Sarici D, Akin MA, Kurtoglu S, Gunes T, Ozturk MA, Akcakus M: Thyroid functions of neonates with Down syndrome. Ital J Pediatr 2012;38:44-46.

21. Tüysüz B, Beker DB: Thyroid dysfunction in children with Down's syndrome. Acta Paediatr 2001;90:1389-1393.

22. Meyerovitch J, Antebi F, Greenberg-Dotan S, Bar-Tal O, Hochberg Z: Hyperthyrotropinaemia in untreated subjects with Down's syndrome aged 6 months to 64 years: a comparative analysis. Arch Dis Child 2012; 97:595-598.

23. Claret C, Goday A, Benaiges D, Chillarón JJ, Flores JA, Hernandez E, Corretger JM, Cano JF:Subclinical hypothyroidism in the first years of life in patients with Down syndrome. Pediatr Res 2013; 73:674-678. 
24. King K, O'Gorman C, Gallagher S: Thyroid dysfunction in children with Down syndrome: a literature review. Ir J Med Sci 2014; 183:1-6.

25. Graber E, Chacko E, Regelmann MO, Costin G, Rapaport R: Down syndrome and thyroid function. Endocrinol Metab Clin North Am 2012; 41:735-745.

26. Luton D, Azria E, Polak M, Carré A, Vuillard E, Delezoide AL, Guibourdenche J: Thyroid function in fetuses with down syndrome. Horm Res Paediatr 2012; 78:88-93.

27. Sharav T, Landau H, Zadik Z, Einarson TR: Age-related patterns of thyroid-stimulating hormone response to thyroitropin-releasing hormone stimulation in Down syndrome. Am J Dis Child 1991; 145:172175.

28. Faria CD, Ribeiro S, Kochi C, Silva AP, Ribeiro BN, Marçal LT, Santos FH, Eduardo CP, Monte O, Longui CA: TSH neurosecretory dysfunction (TSH-nd) in Down syndrome (DS): low risk of progression to Hashimoto's thyroiditis. Arq Bras Endocrinol Metabol 2011; 55:628-631.

29. Ivarsson SA, Ericsson UB, Gustafsson J, Forslund M, Vegfors P, Annerén G: The impact of thyroid autoimmunity in children and adolescents with Down syndrome. Acta Paediatr 1997; 86:1065-1067. 30. van Trotsenburg AS, Vulsma T, van Rozenburg-Marres SL, van Baar AL, Ridder JC, Heymans HS, Tijssen JG, de Vijlder JJ: The effect of thyroxine treatment started in the neonatal period on development and growth of two-year-old Down syndrome children: a randomized clinical trial. J Clin Endocrinol Metab 2005;90:3304-3311.

31. Aversa T, Lombardo F, Valenzise M, Messina MF, Sferlazzas C, Salzano G, De Luca F, Wasniewska M: Peculiarities of autoimmune thyroid diseases in children with Turner or Down syndrome: an overview. Ital J Pediatr 2015; 14:410-416.

32. Popova G, Paterson WF, Brown A, Donaldson MD: Hashimoto's thyroiditis in Down's syndrome: clinical presentation and evolution. Horm Res 2008;70:278-284.

33. Nicholson LB, Wong FS, Ewins DL, Butler J, Holland A, Demaine AG, McGregor AM: Susceptibility to autoimmune thyroiditis in Down's syndrome is associated with the major histocompatibility class II DQA 0301 allele. Clin Endocrinol (Oxf) 1994; 41:381-383.

34. Kowalczyk K, Pukajło K, Malczewska A, Król-Chwastek A, Barg E: L-thyroxine therapy and growth processes in children with Down syndrome. Adv Clin Exp Med 2013; 22:85-92. 
35. Prasher V, Gomez G: Natural history of thyroid function in adults with Down syndrome - 10-year follow-up study. J Intellect Disabil Res 2007;51:312-317.

36. Prasher V, Ninan S, Haque S: Fifteen-year follow-up of thyroid status in adults with Down syndrome. J Intellect Disabil Res 2011;55:392-396.

37. McGowan S, Jones J, McMillan D, McLaughlin K, Smith S, Leyland K, Charleton P, Donaldson M; Scottish Down Syndrome Screening Group: Screening for hypothyroidism in Down syndrome using the capillary thyroid stimulating hormone method. J Pediatr 2015;166:1013-1017.

38. Tenenbaum A, Lebel E, Malkiel S, Kastiel Y, Abulibdeh A, Zangen DH: Euthyroid submedian free T4 and subclinical hypothyroidism may have a detrimental clinical effect in Down syndrome. Horm Res Paediatr 2012;78:113-118.

39. Karlsson B, Gustafsson J, Hedov G, Ivarsson SA, Annerén G: Thyroid dysfunction in Down's syndrome: relation to age and thyroid autoimmunity. Arch Dis Child 1998; 79:242-245.

40. Hoey H, Murphy J: Down Syndrome Medical Interest Group (DSMIG). Medical Management of Children and Adolescents with Down Syndrome in UK and Ireland. 2001.

41. Bull $\mathrm{Mj}$ and The Committee and the Committee on Genetics of the American Academy of Pediatrics: Health supervision for children with Down syndrome. Pediatrics 2011; 128:393-406.

42. Tracy J: Australians with Down syndrome - Health matters. Aust Fam Physician 2011; 40:202-208.

43. van Cleve S, Cohen W: Part I: Clinical practice guidelines with Down Syndrome from birth to 12 years. J Pediatr Health Care 2006; 20:47-54.

44. van Cleve S, Cohen W: Part II: Clinical practice guide- lines for adolescents and young adults with Down syndrome: 12-21 years. J Pediatr Health Care 2006; 20:198-205.

45. National Primary Care Research and Development Centre and University of York Health Economics Consortium (NICE External Contractor). Health economic report for the indicator NM04: Percentage of patients on the Learning Disabilities register with Down's Syndrome aged 18 and over who have a record of blood TSH in the past year (excluding those who are on the thyroid register). July 2009. https://www.nice.org.uk/Media/Default/standards-andindicators/qof\%20indicator\%20key\%20documents/NM01\%20Cost\%20effectiveness\%20analysis.pdf 
G, Arrigo T: Peculiarities of Graves' disease in children and adolescents with Down's syndrome. Eur J Endocrinol 2010; 162:591-595.

47. Goday-Arno A, Cerda-Esteva M, Flores-Le-Roux JA, Chillaron-Jordan JJ, Corretger JM, Cano-Pérez JF: Hyperthyroidism in a population with Down syndrome (DS). Clin Endocrinol (Oxf) 2009; 71:110-114.

48. Aversa T, Lombardo F, Corrias A, Salerno M, De Luca F, Wasniewska M: In young patients with Turner or Down syndrome, Graves' disease presentation is often preceded by Hashimoto's thyroiditis. Thyroid $2014 ; 24: 744-747$.

49. Schmidt F, Kapellen TM, Wiegand S, Herbst A, Wolf J, Fröhlich-Reiterer EE, Rabl W, Rohrer TR, Holl RW; DPV-Wiss Study Group; BMBF Competence Network Diabetes: Diabetes mellitus in children and adolescents with genetic syndromes. Exp Clin Endocrinol Diabetes 2012; 120:579-585.

50. Bergholdt R, Eising S, Nerup J, Pociot F: Increased prevalence of Down's syndrome in individuals with type 1 diabetes in Denmark: A nationwide population-based study. Diabetologia 2006; 49:1179-1182.

51. Gillespie KM, Dix RJ, Williams AJ, Newton R, Robinson ZF, Bingley PJ, Gale EA, Shield JP: Islet autoimmunity in children with Down's syndrome. Diabetes 2006; 55:3185-3188.

52. Rohrer TR, Hennes P, Thon A, Dost A, Grabert M, Rami B, Wiegand S, Holl RW; DPV Initiative: Down's syndrome in diabetic patients aged $<20$ years: an analysis of metabolic status, glycaemic control and autoimmunity in comparison with type 1 diabetes. Diabetologia 2010; 53:1070-1075.

53. Burch PR, Milunsky A: Early-onset diabetes mellitus in the general and Down's syndrome populations. Genetics, aetiology, and pathogenesis. Lancet 1969; 1:554-558.

54. Shield JP, Wadsworth EJ, Hassold TJ, Judis LA, Jacobs PA: Is disomic homozygosity at the APECED locus the cause of increased autoimmunity in Down's syndrome? Arch Dis Child 1999; 81:147-150.

55. Aitken RJ, Mehers KL, Williams AJ, Brown J, Bingley PJ, Holl RW, Rohrer TR, Schober E, AbdulRasoul MM, Shield JP, Gillespie KM: Early-onset, coexisting autoimmunity and decreased HLA-mediated susceptibility are the characteristics of diabetes in Down syndrome. Diabetes Care 2013; 36:1181-1185.

56. Fulcher T, Griffin M, Crowley S, Firth R, Acheson R, O'Meara N: Diabetic retinopathy in Down's syndrome. Br J Ophthalmol 1998;82:407-409. 